\title{
Retraction Note to: Anterior Cervical Discectomy and Fusion with a Compressive C-JAWS Staple
}

Lei Xia, Ming-Xing Liu, Jun Zhong, Ning-Ning Dou, and Massimiliano Visocchi

\section{Retraction Note to:}

Chapter 23 in: M. Visocchi et al. (eds.), Trends in Reconstructive Neurosurgery, Acta Neurochirurgica Supplement 124, DOI 10.1007/978-3-319-39546-3_23

This chapter has been retracted at the request of the author in agreement with the editor. The article has been already accepted by a journal, and it can be searched in pubmed: Xia L, Liu MX, Zhong J. et al. Anterior cervical discectomy \& fusion with a compressive staple of C-JAWS [J]. British Journal of Neurosurgery. 2016, Jun 22:1-5.

The updated original online version for this chapter can be found at DOI 10.1007/978-3-319-39546-3_23 